\title{
Prediction of Transcriptional Regulatory Networks for Retinal Development
}

\author{
Ying $\mathrm{Li}^{1}$, Haiyan Huang ${ }^{2}$ and $\mathrm{Li} \mathrm{Cai}^{1}$ \\ ${ }^{1}$ Department of Biomedical Engineering, Rutgers University, NJ \\ 2Department of Statistics, University of California, Berkeley, CA
}

USA

\section{Introduction}

The formation of the neatly layered retina during embryonic development is dictated by a series of complicated transcription factor interactions. Retina-specific expression of these transcription factors is an essential step in establishing retinal progenitor cells (RPCs) from embryonic stem cells. The transcriptional control of gene expression is largely mediated by the combinatorial interactions between cis-regulatory DNA elements and trans-acting transcription factors, which cooperate/interact with each other to form a transcription regulatory network during this developmental process. Such regulatory networks are essential in regulating tissue/cell-specific gene expression, e.g., in cell fate determination and differentiation during embryonic retinal development (Hu et al., 2010; Kumar, 2009; Swaroop et al., 2010). Many genes, which involved in transcriptional networks for the specification of a certain retinal cell lineage, have already been identified and characterized (Corbo et al., 2010; Kim et al., 2008b; Tang et al., 2010). The transcriptional regulatory networks for specific retinal cell lineages, e.g., the photoreceptors (Corbo et al., 2010; Hsiau et al., 2007) and bipolar neurons (Kim et al., 2008b), were established in recent years. However, the transcriptional regulatory network that governs the entire neural retinal development is still elusive.

Identifying tissue/cell-specific cis-regulatory elements, trans-acting factor binding sites (TFBSs), and their binding transcription factors (TFs) represent key steps towards understanding tissue/cell-specific gene expression and further successful reconstruction of transcriptional regulatory networks. These steps also present major challenges in both fields of experimental biology and computational biology.

Currently, the prevailing method of studying TFBSs and transcriptional regulatory networks is to determine the function of tissue-specific trans-acting factors based on data from genome-wide gene expression profiling and chromatin immunoprecipitation (ChIP). ChIP is often used to investigate protein-DNA interactions in a cell. Coupled with massive parallel sequencing, ChIP-seq is capable of mapping the genome-wide protein-DNA interaction at a finer resolution (Valouev et al., 2008) to identify candidate enhancer sequences (Visel et al., 2009). Thus, a regulatory cascade can be recognized via consequential analysis of the factors involved.

Here, we present a new method for the computational analysis of TFBSs and transcriptional regulatory networks utilizing genome-wide sequencing, expression, and enhancer data. In 
contrast to the traditional method, which mainly focuses on factor expression analysis, we emphasize the sequence elements with tissue-specific enhancer activity. Our hypothesis is that enhancers, non-coding sequences that direct gene expression in a cell-/tissue-specific manner, contain common TFBSs that allow the key protein factors (important for the development of that cell/tissue type) to bind. Experimentally verified tissue-specific enhancer elements selected from enhancer databases were carefully screened for common trans-acting factor binding sites to predict potential sequence-factor interacting networks. DNA-binding protein factors that associate with multiple enhancers can be analyzed using experimental methods.

As proof-of-principle, simple transcriptional regulatory networks of embryonic retinal development were assembled based on common/key factors and their interacting genes, as determined by literature search. These resulting networks provide a general view of embryonic retinal development and a new hypothesis for further experimentation.

\section{Methods and results}

In this study, we aimed to develop a method for the identification of regulatory networks for cell/tissue-specific gene expression. To test our hypothesis of the existence of common TFBSs on the enhancers of cell/tissue specific genes, we employ the mouse developing retina as a model system. Enhancers that direct retina-specific gene expression were selected and their sequences were thoroughly screened for common TFBSs and trans-acting factors (protein factors) using open-access software such as TESS, JASPA, MatInspector, and MEME, etc. For common TFBS selection, we developed a Matlab program. These common protein factors were further studied for their expression profiles. Thereafter, we were able to construct transcriptional regulatory networks based on the known function of the enhancerbinding trans-acting factors using a network construction tool, BioTapestry (Longabaugh et al., 2009).

\subsection{Retina-specific enhancers}

To determine the transcriptional regulatory networks that govern retinal development, we identified and selected enhancer elements that direct gene expression in the retina by searching the VISTA Enhancer Browser. The VISTA Enhancer Browser is a central resource for experimentally validated human and mouse non-coding DNA fragments with enhancer activity as assessed in transgenic mice. Most of these non-coding elements were selected for testing based on their extreme conservation in other vertebrates or epigenomic evidence (ChIP-Seq) of putative enhancer marks. The results of this in vivo enhancer screen are provided through this publicly available website (Frazer et al., 2004). Of the 1503 noncoding DNA elements from human and mouse genomes that were tested for their ability to direct gene expression on embryonic day 11.5 (E11.5) using a reporter assay in transgenic mouse, a total of 47 elements were shown to possess enhancer activity in the retina (as of February 10, 2011). Of the 47 elements, 25 show enhancer activities in both the retina and other tissues, e.g., heart, limb, brain and spinal cord, etc. These 25 elements were separated for further analysis as we focused on retina-specific sequence elements. In addition, among the 22 remaining elements, 17 elements were active enhancers in the retina in at least half of the tested transgenic embryos (Supporting data 1). To further increase the possibility of identifying the key enhancer elements that are critical for retinal development, we applied more stringent selection criteria based on the following two properties: 1) the reporter 
expression is restricted in the retina and not in any other regions of the CNS; 2) there is expression of at least one of the flanking genes in the retina at E11.5 (or Theiler Stage 18-21). The second category was applied because a majority of known enhancers were found in the immediate up- or downstream region of their target genes, and thus the regulatory activities of enhancers were considered to be most likely associated with their flanking genes. Any enhancer elements that did not fit into at least one of the two categories was thus eliminated (details in Supporting data 5). Based on the above criteria, 8 enhancer elements were identified (Table 1).

\begin{tabular}{|c|c|c|c|c|c|c|}
\hline \multirow[t]{2}{*}{ Group } & \multirow[t]{2}{*}{$\begin{array}{c}\text { Enhancer } \\
\text { ID }\end{array}$} & \multirow[t]{2}{*}{$\begin{array}{c}\text { Length } \\
(\mathrm{bp})\end{array}$} & \multirow{2}{*}{$\begin{array}{c}\text { Reporter expression } \\
\text { pattern derived } \\
\text { from enhancer } \\
\text { activity }\end{array}$} & \multirow[t]{2}{*}{$\begin{array}{l}\text { Annotation of } \\
\text { reporter expression }\end{array}$} & \multicolumn{2}{|c|}{$\begin{array}{c}\text { Flanking genes of enhancers and } \\
\text { their endogenous expression in } \\
\text { mouse embryos }\end{array}$} \\
\hline & & & & & Upstream & Downstream \\
\hline \multirow{4}{*}{1} & hs27 & 1113 & eye $(4 / 6), \operatorname{limb}(4 / 6)$ & Retina + non-CNS & $\begin{array}{l}\text { Irx5: E11-19 } \\
\text { retina }\end{array}$ & $\begin{array}{l}\text { Irx6: E11-19 } \\
\text { retina }\end{array}$ \\
\hline & hs258 & 1487 & eye(3/5), limb, & Retina + non-CNS & Ccdc39: & $\begin{array}{l}\text { Fxr1: E12-14, E19 } \\
\text { retina }\end{array}$ \\
\hline & hs546 & 1753 & eye(7/7), limb, nose & Retina + non-CNS & $\begin{array}{l}\text { Nr2f1: E11-19 in } \\
\text { retina }\end{array}$ & Arrdc3: E14-19 \\
\hline & hs1170 & 1288 & eye(8/8) & Retina & $\begin{array}{l}\text { Nr2f1: E11-19 in } \\
\text { retina }\end{array}$ & Arrdc3: E14-19 \\
\hline \multirow{2}{*}{2} & hs932 & 775 & $\begin{array}{r}\text { eye }(6 / 9), 1 \\
\text { branchi }\end{array}$ & Retina + non-CNS & $\begin{array}{l}\text { AA408296: } \\
\text { unknown }\end{array}$ & Irf6: not in retina \\
\hline & $\operatorname{mm} 165$ & 926 & eye $(4 / 5)$, heart & Retina + non-CNS & Lao1: & $\begin{array}{l}\text { Slc2a1: not in } \\
\text { retina }\end{array}$ \\
\hline \multirow{2}{*}{3} & hs1122 & 1218 & eye(6/7) & Retina + Spinal cord & $\begin{array}{l}\text { Ascl1: E11-19 in } \\
\text { retina (MGI) }\end{array}$ & Pah: not in retina \\
\hline & $\mathrm{mm} 269$ & 760 & $\begin{array}{l}\text { eye }(5 / 5), \text { heart, } \\
\text { other }\end{array}$ & Retina+ Spinal cord & \multicolumn{2}{|c|}{$\begin{array}{l}\text { Zfand5 (intragenic): E11-13/E13-19 } \\
\text { in retina }\end{array}$} \\
\hline
\end{tabular}

Table 1. A list of eight retina-specific enhancers. The 8 retina-specific enhancers selected from the VISTA Enhancer Browser are listed above. They are grouped into 3 sub-groups according to the reporter expression in mouse embryos derived from these enhancers and the expression pattern of their flanking genes. The enhancer IDs, their expression pattern and the flanking gene names were retrieved directly from VISTA Enhancer Browser, with an expression pattern described as 'tissue type (positive sample number/total sample number)'. Flanking genes with expression in the retina are shown in bold.

\subsection{Trans-acting factor binding sites on retina-specific enhancers}

The binding of trans-acting factors (e.g., transcription factors) to non-coding regulatory DNA (e.g., promoters, enhancers, etc.) is an essential process in the control of gene expression. This protein-DNA interaction helps recruit the DNA polymerase complex and co-activators to form the transcription machinery. The binding of these protein factors can also act as repressors to prevent transcription. Identification of a TFBS in the enhancer and promoter for a gene may indicate the possibility that the corresponding factors play a role in the regulation of that gene. Importantly, the ability of an enhancer to direct cell/tissuespecific gene expression is achieved via the binding of tissue-specific trans-acting protein 
factors. To determine what protein factors regulate retina-specific gene expression, it is important to determine what TFBSs are located on the retina-specific enhancers. We thus searched DNA sequences of the 8 retina-specific enhancer elements for their known TFBSs using TESS (Schug, 2002), JASPA (Portales-Casamar et al., 2010; Sandelin et al., 2004) and MatInspector (Cartharius et al., 2005). For example, TESS (Transcription Element Search System - http://www.cbil.upenn.edu/cgi-bin/tess) is a web tool for predicting TFBSs in DNA sequences. It can identify TFBSs using site or consensus strings and positional weight matrices mainly from the TRANSFAC (Knuppel et al., 1994). TRANSFAC contains data on transcription factors, their experimentally-proven binding sites, and regulated genes. Its broad compilation of binding sites allows the derivation of positional weight matrices (Knuppel et al., 1994). The following search parameters were set when searching TESS: a minimum string length of 6 , a maximum allowable string mismatch of $10 \%$, a minimum loglikelihood ratio score of 12, and organism selection of Mus musculus (the house mouse). Our search results show that there are approximately 150 TFBSs for each of the 8 enhancer sequences (Supporting data 2). Similar results were reported by JASPA and MatInspector. The corresponding protein factors of these TFBSs were considered to be capable of binding with the 8 retina-specific enhancers, and thus they are important in activating/suppressing gene expression in the retina.

\subsection{A motif containing Pou3f2 binding sites}

Since all 8 enhancers possess the ability to direct retina-specific gene expression, there may be key TFBSs shared amongst these retina-specific sequence elements. To test this hypothesis, we sorted and screened the TFBSs of each of the 8 enhancers to identify common ones using a Matlab program that we developed for this study (Supporting data 6). This Matlab program for common TFBS selection was designed to compare the TFBSs on each of the retina-specific enhancer elements predicted by TESS. TFBSs for two or three different enhancers can be sequentially compared. A "model" character was used as the comparison category instead of the binding site name in both TESS and our Matlab program. As defined in TESS, a model is "the site string or weight matrix used to pick this site" (Schug, 2002), and thus describes the nature of a binding site. One factor may have multiple models, and one model may be shared by multiple factors. The model character is the only necessary parameter to characterize the transcription factors depending on their binding site property. With this sorting/searching program, we identified a TFBS for Pou3f2 (also known as Brn2) that was present in all 8 retina-specific enhancers (Fig. 1A). Previous studies have demonstrated that the Pou3f2 transcription factor plays an important role in the development of neural progenitor cells (Catena et al., 2004; Kim et al., 2008b; McEvilly et al., 2002; Sugitani et al., 2002). Furthermore, the literature reports that this motif was first discovered as a cis-element in the Chx10 enhancer, which can drive reporter expression in intermediate and late RPCs (Rowan and Cepko, 2005). In this study, Pou3f2 was also shown to affect bipolar interneuron fate determination through interactions with Chx10 and Nestin. We thus speculate that this Pou3f 2 binding site may exist in regulatory sequences among genes important for the development of neural retinal progenitor cells (RPCs). Therefore, the cis-elements of Chx10, Cyclin D1, Pax6, Rax, and Six3 were examined because these genes are known for their role in regulating RPC development and retinal cell differentiation (Conte et al., 2010; Martinez-de Luna et al., 2010; Oliver et al., 1995; Rowan and Cepko, 2005; Sicinski et al., 1995). Confirming our prediction, Pou3f2 binding sites were also present in the cis-elements of Chx10, Cylin D1, and Pax6 genes (sequences can be found 
in Supporting data 4). Next, sequence alignment analysis was performed to identify a common motif for Pou3f2 binding sites using MEME (Multiple Em for Motif Elicitation, http://meme.sdsc.edu/meme4_4_0/cgi-bin/meme.cgi) (Bailey and Elkan, 1994). It is commonly believed that there are dependencies among different positions in a motif. MEME may ignore such kind of dependency. Sequence alignment reveals a $22 \mathrm{bp}$ motif containing two Pou3f 2 binding sites among all 8 enhancer elements (with a stringent Evalue of $7.2 \mathrm{e}-20$ and p-value < 3.02e-6) and also in the cis-elements of RPC-specific genes, e.g., Chx10, CyclinD1, and Pax6, from multiple vertebrate species (Fig. 1B). In addition, a line of evidence indicates that Pou3f2 binds to the Rax enhancer to regulate the expression of Rax in RPCs (Martinez-de Luna et al., 2010). Such prevalent existence of repeated Pou3f2 binding sites among retina-specific enhancer elements and cis-elements of RPC-specific genes suggests that Pou3f2 is a key regulatory factor in the embryonic retinal development.
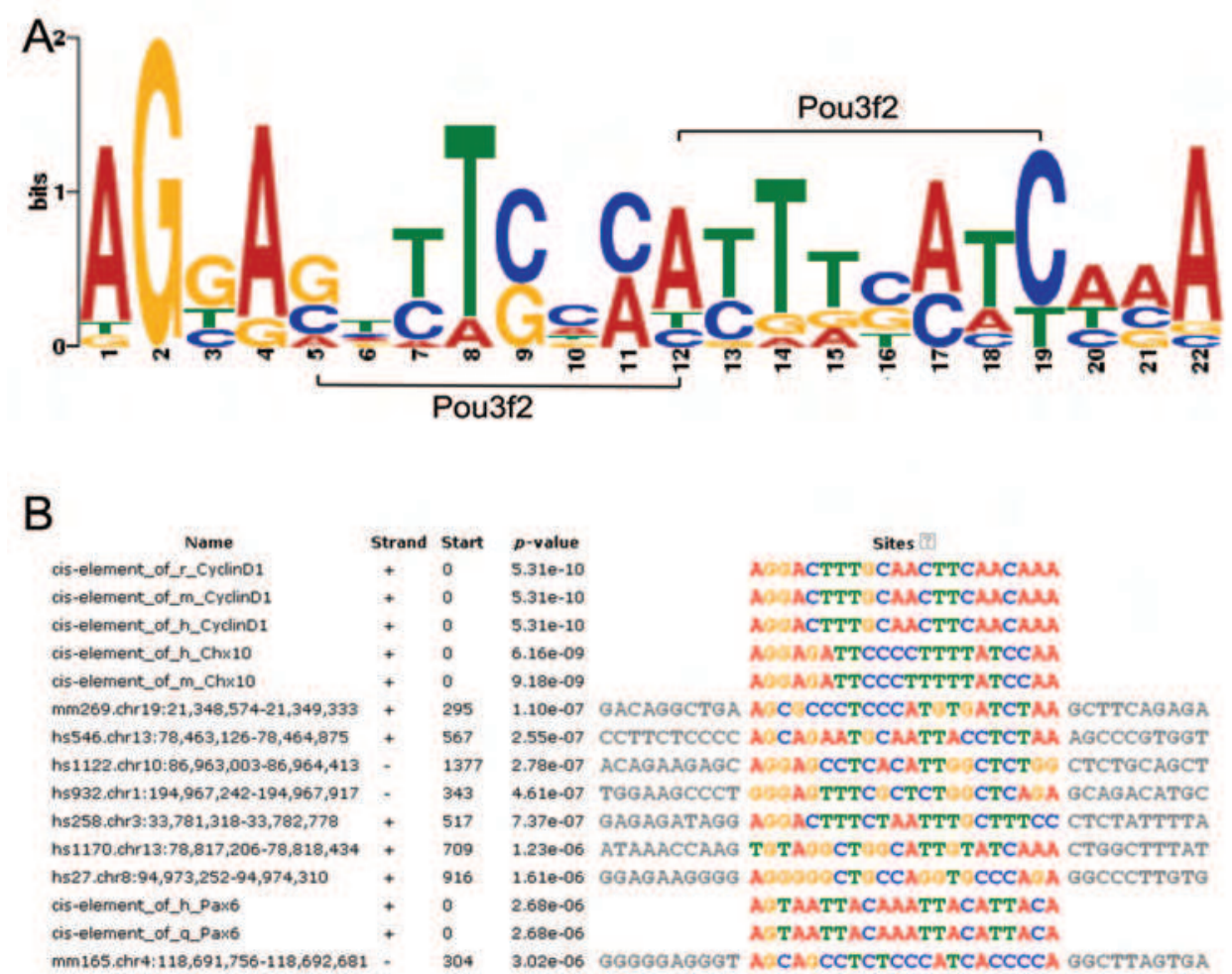

Fig. 1. A $22 \mathrm{bp}$ motif is present in all 8 retina-specific enhancers and cis-elements of retinal progenitor gene Chx10, CyclinD1 and Pax6. Sequence alignment was performed using MEME and the output shows a motif exists among all above 15 sequences ( $p$-value $<3 e-6)$. A. a SeqLog presentation of the 22bp motif. Dual binding sites of Pou3f2 were located next to each other forms Pou $3 \mathrm{f} 2$ binding site repeats. B. sequence alignment reveals the $22 \mathrm{bp}$ motif among the 8 enhancers and cis-elements of RPC-specific genes (e.g., Chx10, CyclinD1 and Pax6) (Rowan and Cepko, 2005). Abbreviation: r, rat; $\mathrm{m}$, mouse; h, human; q, quail. $\mathrm{RPC}$, retinal progenitor cell. 


\subsection{Key trans-acting factors involved in transcriptional regulatory networks of retinal development}

It is unlikely that only one factor (i.e., Pou3f2) is involved in regulating retina-specific gene expression. Trans-acting factors often do not function alone but rather in a cooperative manner. To identify other key protein factors for retina-specific gene expression, we applied the following assumptions to the enhancer elements and their binding trans-acting factors:

1. Key TFBSs should be common to all or a subset of retina-specific enhancer elements;

2. The flanking genes of these enhancer elements should be expressed in the retina during early retinal development, because an enhancer often regulates the expression of its flanking gene(s);

3. The binding factors should have a known function in retinal development, or

4. If the binding factors have an unknown function in retinal development, they should be at least expressed in the retina during retinal development. In this case, the expression of the factor provides novel hypothesis for their function in retinal development, which needs to be tested by functional studies.

Based on the above assumptions, the information on the expression of the flanking genes of enhancer elements in the developing retina is necessary for the TFBS analysis. Five databases of gene expression (see Table 2) were searched. The information on the expression of these flanking genes were retrieved from these databases (Tables 1, 4 and supporting data 3). The factors that do not express in the retina during embryonic retinal development, e.g., around E11.5 (when enhancer elements were active), were set aside for further analysis of retinal transcriptional regulatory networks. We then searched common TFBSs among subsets of the 8 retina-specific enhancers. The TFBSs common to individual different subgroups were combined. In addition to Pou3f2, five other factors (i.e., Crx, Hes1, Meis1, Pbx2, and Tcf3) were identified (Table 3). Four of the 6 factors have known functions in retinal development, which is consistent with our hypothesis. The last two factors do not have known functions in the retina. However, the prediction of their binding with groups of enhancers suggests they play a role during retinogenesis. As the binding sites of these 6 factors were shared among a subset of retina-specific enhancer elements, these 6 binding trans-acting factors were predicted as the key factors that participate in regulating retinaspecific gene expression during embryonic development.

\begin{tabular}{|l|l|l|}
\hline Database & Source & Reference \\
\hline $\begin{array}{l}\text { Gene expression database (emage) } \\
\text { of Edinburg Mouse Atlas Project } \\
\text { (EMAP, v5.0_3.3) }\end{array}$ & $\begin{array}{l}\text { http://www.emouseatlas.org/e } \\
\text { mage/ }\end{array}$ & $\begin{array}{l}\text { (Richardson et al., } \\
\text { 2010) }\end{array}$ \\
\hline $\begin{array}{l}\text { Gene Expression Database in } \\
\text { Mouse Genome Informatics (MGI, } \\
\text { version 4.4) }\end{array}$ & http://www.informatics.jax.org & (Finger et al., 2011) \\
\hline Eurexpress & http://www.eurexpress.org & $\begin{array}{l}\text { (Diez-Roux et al., } \\
\text { 2011) }\end{array}$ \\
\hline VisiGene Image Browser & $\begin{array}{l}\text { http://genome.ucsc.edu/cgi- } \\
\text { bin/hgVisiGene }\end{array}$ & (Kent et al., 2002) \\
\hline $\begin{array}{l}\text { Genome-scale mouse brain } \\
\text { transcription factor expression } \\
\text { analysis }\end{array}$ & Supplementary data S4 and S6 & (Gray et al., 2004) \\
\hline
\end{tabular}

Table 2. A list of gene expression databases used in this study. 


\begin{tabular}{|c|l|l|l|l|}
\hline Factor & Binding site & Known function & Expression pattern & $\begin{array}{l}\text { Presence in } \\
\text { enhancer } \\
\text { element }\end{array}$ \\
\hline Pou3f2 & ATTTGCAT & Induce Bipolar cells & $\begin{array}{l}\text { E10.5-14.5 in retina; } \\
\text { diencephalon, future } \\
\text { midbrain, future SC, } \\
\text { rhombencephalon }\end{array}$ & All 8 elements \\
\hline Crx & $\begin{array}{l}\text { tgaggGGATCA } \\
\text { Acagact }\end{array}$ & Induce Photoreceptors & E11-adult in retina & $\begin{array}{l}\text { hs27, hs258, } \\
\text { hs546, hs1170 }\end{array}$ \\
\hline Hes1 & CTTGTG & $\begin{array}{l}\text { Repress Amacrine, } \\
\text { Horizontal, and } \\
\text { Ganglion cells; } \\
\text { Induce Photoreceptors }\end{array}$ & $\begin{array}{l}\text { E11-13 in retina, } \\
\text { thalamus, hypothalamus, } \\
\text { striatum, olfactory } \\
\text { epithelial }\end{array}$ & $\begin{array}{l}\text { hs27, hs258, } \\
\text { hs1170 }\end{array}$ \\
\hline Meis1 & $\begin{array}{l}\text { CTGTCActaaga } \\
\text { tgaca }\end{array}$ & $\begin{array}{l}\text { retinal cell fate } \\
\text { determination }\end{array}$ & $\begin{array}{l}\text { E10.5-14.5 in retina, lens } \\
\text { vesicle, diencephalon, } \\
\text { future sc, hindbrain }\end{array}$ & $\begin{array}{l}\text { hs27, hs258, } \\
\text { hs546, hs1170, } \\
\text { hs932, mm165 }\end{array}$ \\
\hline Pbx-2 & $\begin{array}{l}\text { CacctgagagTGA } \\
\text { CAgaaggaaggc }\end{array}$ & $\begin{array}{l}\text { No function known in } \\
\text { retina }\end{array}$ & $\begin{array}{l}\text { E10.5-14.5 in retina, } \\
\text { thalamus, midbrain, } \\
\text { hindbrain, sc, ear }\end{array}$ & $\begin{array}{l}\text { hs27, hs258, } \\
\text { hs546, hs1170, } \\
\text { hs932, mm165 }\end{array}$ \\
\hline $\begin{array}{l}\text { TcaccagCACCT } \\
\text { Gtc }\end{array}$ & $\begin{array}{l}\text { No function known in } \\
\text { retina }\end{array}$ & $\begin{array}{l}\text { E13.5 in retina (MGI) } \\
\text { ha27, hs258, } \\
\text { hs546, hs1170 }\end{array}$ \\
\hline
\end{tabular}

Table 3. A list of binding factors that show their temporal and spatial co-localization of expression with each group of enhancers. For each factor, elements shown in the last column indicate the enhancer elements which share a potential common binding with it. The 'Expression pattern' column shows available evidence of the co-localization with enhancers. Corresponding databases are noted because different databases recorded different expression pattern for the corresponding factor. The general function of each factor is also included for future reference. Abbreviation: RPC, retinal progenitor cell; B, bipolar cell; A, amacrine cell; $\mathrm{H}$, horizontal cell; G, ganglion cell; PR, photoreceptor cell; sc, spinal cord.

\begin{tabular}{|c|l|}
\hline Gene & Function (related to retina development) and reference \\
\hline Ascl1 & $\begin{array}{l}\text { With Mash3, regulate the neuron/glia fate determination (Hatakeyama et al., } \\
\text { 2001); with Mahs3 and Chx10, specify Biopolar cell identity (Satow et al., 2001). }\end{array}$ \\
\hline Irx5 & $\begin{array}{l}\text { Off circuit subsets of bipolar interneuron (Cheng et al., 2005; Cohen et al., 2000; } \\
\text { Kerschensteiner et al., 2008). }\end{array}$ \\
\hline Irx6 & $\begin{array}{l}\text { No known clear function in retina. But It expresses in the in the area lining the } \\
\text { lumen of the otic vesicle including the region giving rise to ganglion complex of } \\
\text { CN VII/VIII at E11.5 through E16.5 and overlaps with Mash1 (Cohen et al., } \\
\text { 2000; Mummenhoff et al., 2001) }\end{array}$ \\
\hline Fxr1 & Retina pigmentation(de Diego Otero et al., 2000); other function not known. \\
\hline Nr2f1 & $\begin{array}{l}\text { Amacrine development, may involve in cone differentiation; express in a } \\
\text { unique gradient in retina along D/V axis (Inoue et al., 2010). }\end{array}$ \\
\hline Zfand5 & No known function in retina. \\
\hline
\end{tabular}

Table 4. A list of flanking genes with their function and references 
Interestingly, three common TFBSs (i.e., Pou3f2, Crx, and Meis1) were present among enhancer elements hs27, hs258, and hs1170 (see Tables 1, 3). Sequence alignment of the three enhancer elements and cis-elements of RPC-specific genes (e.g., Chx10, Cyclin D1, and Pax6) revealed another $22 \mathrm{bp}$ motif (Fig. 2). Crx binding sites were present on enhancer elements hs546 and hs1170, while Hes1 binding sites were present on enhancer element hs546. Since these two enhancer elements (hs1170 and hs546) were both located in the non-coding region between Nr2f1 and Arrdc3, and since Arrdc3 was not active at E11.5 in the retina, the binding of Crx and Hes1 may participate in regulating the expression of Nr2f1. This result is supported by the finding that both Crx (Peng et al., 2005) and Nr2f1 (Inoue et al., 2010; Satoh et al., 2009) play a role in inducing photoreceptor cell fate, though at different stages. In addition, Crx has been shown to be expressed in bipolar cells, paired with Otx2 and Pou3f2, in binding with a 164bp Chx10 enhancer (Kim et al., 2008a). Hes1 has been shown to be active during early eye formation. By suppressing Math5, Hes1 was shown to be involved in the development of cone photoreceptors, amacrine, horizontal and ganglion cells from the RPCs (Le et al., 2006; Lee et al., 2005).

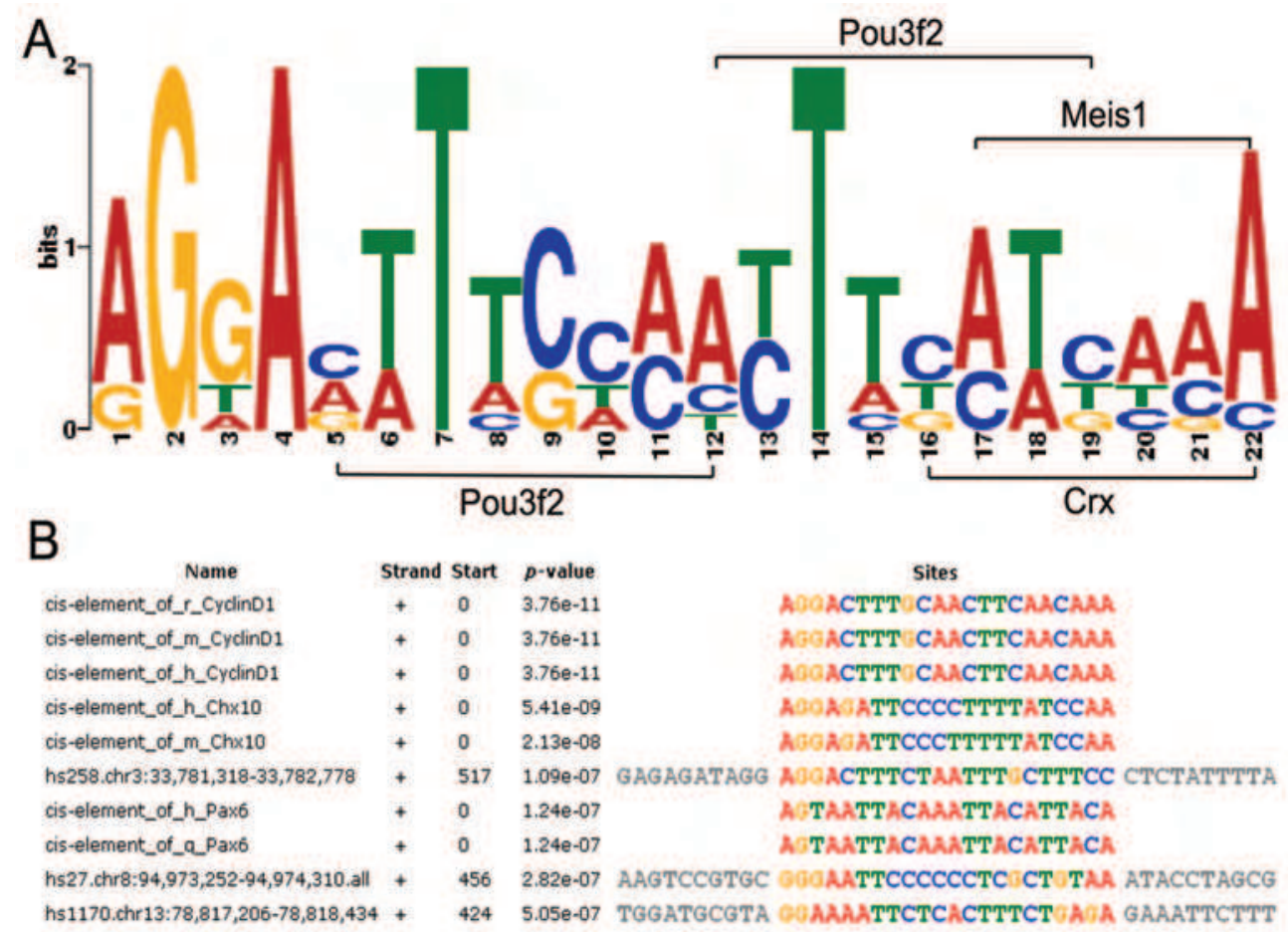

Fig. 2. A $22 \mathrm{bp}$ motif is present in a subset of enhancer elements and cis-elements of RPCspecific genes, (e.g., Chx10, Cyclin D1, Pax6). Sequence alignment was performed using MEME among enhance elements (hs258, hs546, and hs1170) and cis-elements of genes Chx10, Cyclin D1, Pax6. A. a SeqLog presentation of the 22bp motif. This 22 bp motif contains binding sites for 3 factors: Pou3f2, Meis1 and Crx. B. Sequence alignment between elements mentioned above. Abbreviation: $r$, rat; m, mouse; h, human; q, quail. 
Meis1 together with Meis2, as members of the TALE-homeodomain protein Homothorax (Hth) related protein family, were known to be expressed in the RPCs of mouse and chick (Heine et al., 2008). Meis1 was expressed in RPCs throughout the entire neurogenesis period, and Meis2 was expressed more specifically in RPCs before the initiation of retina differentiation. Together, they function to maintain the RPCs in a rapid proliferating state and control the expression of other ocular genes, e.g., Pax6, CyclinD1, Six3 and Chx10 (Bessa et al., 2008; Heine et al., 2008). Since Meis1 binding sites are present in a subset of retinaspecific enhancers, Meis1 may function as an RPC-specific factor. Since the onset of mouse retina neurogenesis is approximately at E10.5 when the ganglion cells first appear (Leo M. Chalupa, 2008). By E11.5, RPCs of all six cell types are highly active. Therefore, binding of Meis1 with enhancers might influence the cell fate of these RPCs.

The presence of common $\mathrm{Pbx} 2$ binding sites may indicate a novel functional role of $\mathrm{Pbx} 2$ in RPCs, since the function of Pbx2 in retinal development has not been documented. Previous studies have shown that Pbx2 is expressed in the zebrafish retina and tectum (French et al., 2007) together with Pbx1 and Meis1, and down-regulation in their expression caused by the deficiency of Prep, the prolyl endopeptidase will lead to eye anomalies (Deflorian et al., 2004; Ferretti et al., 2006). Pbx and Meis proteins are major DNA-binding partners that form abundant complexes (Chang et al., 1997). Thus, there is a possibility that Pbx2 may function in the development of RPCs via the interaction with Meis1 and also regulate other RPCspecific genes (e.g., Irx5, Nr2f1, etc) through enhancer binding (Table 1).

Tcf3 is not yet known to have a function in embryonic retinal development. However, since Tcf3 binding sites are present among the retina-specific enhancer elements, and Tcf3 is expressed in the retina during embryogenesis, its specific function in retinal development needs to be confirmed.

\subsection{Generation of transcriptional regulatory network for early retinal development}

Based on the available expression data from VISTA Enhancer Browser and gene expression databases (Table 2), it is known that these 8 enhancer elements and their common binding trans-acting factors are active during embryonic development in the retina. Among the 8 retina-specific enhancer elements, we have identified 6 common trans-acting factors. These 6 predicted factors are experimentally verified key protein factors known to be involved in regulating gene expression and cell differentiation of progenitor cells during embryonic retinal development (Table 3).

Retina-specific gene expression is most likely determined by two kinds of interactions: (1) the enhancers with their binding protein factors, and (2) the protein factors with their interacting partners. The information about these interactions was used to generate the transcriptional regulatory networks important for retinal development. Therefore, transcriptional regulatory networks of embryonic retina were predicted based on these 6 common/key trans-acting factors (Table 3) and their known interacting partners (Table 5).

To construct retinal transcriptional regulatory networks, a java-based software program named BioTapestry (Longabaugh et al., 2009) (http://www.biotapestry.org/, version 5.0.2) was used to organize the factors and their known interacting partners. BioTapestry is a network facilitating software program designed for dealing with systems that exhibit increasingly complex over time, such as genetic regulatory networks. Its unique annotation system allows the illustration of enhancer-regulated gene expression and connection between factors. Experimental evidence can also be added to network elements after the network was built, as a proof of particular interactions. We only used the presenting 
function of BioTapestry here to show the networks of retinal development during early neurogenesis. For better illustration, the network was mapped according to the 3-layer structure of the mouse retina.

Based on the published information on the interacting factors of these 6 trans-acting factors and their known functions in retinal cell development, we were able to build transcriptional regulatory networks for all six major retinal cell types (Fig. 3). In RPCs, Meis1 is regulated by Prep1 since it has been shown that insufficient Prep1 expression leads to a decrease in Meis1 expression (Deflorian et al., 2004). Meis1 itself can regulate or interact with 4 other factors (e.g., Pax6, CyclinD1, Six3 and Chx10) important to retinal cell differentiation (Bessa et al., 2008; Heine et al., 2008). Crx, interacting with other factors (e.g, Otx2, Nrl and Nr2e3) plays an important role in both cone and rod photoreceptor cell fate determination (Peng et al., 2005). Crx can also influence Chx10 and Irx5 expression to affect the bipolar cell formation (Cheng et al., 2005; Kerschensteiner et al., 2008; Kim et al., 2008a), which is similar to the function of Pou3f2 (Kim et al., 2008a; Rowan and Cepko, 2005) and Otx2 (Kim et al., 2008a). Another important factor is Hes1. Hes1 functions in maintaining RPC proliferation (Wall et al., 2009) and regulating Math5, a critical factor for the generation of amacrine, horizontal, and ganglion cells (Lee et al., 2005). In addition, Hes1 is regulated by Hes6 (Bae et al., 2000). The Nr2f1 gene expresses in the retina in a gradient along the dorsal-ventral axis and has been found to influence the development of amacrine cells. At the same time it can affect cone and rod photoreceptors differentiation (Inoue et al., 2010). The references of all genes/factors in the networks are listed in Table 5.

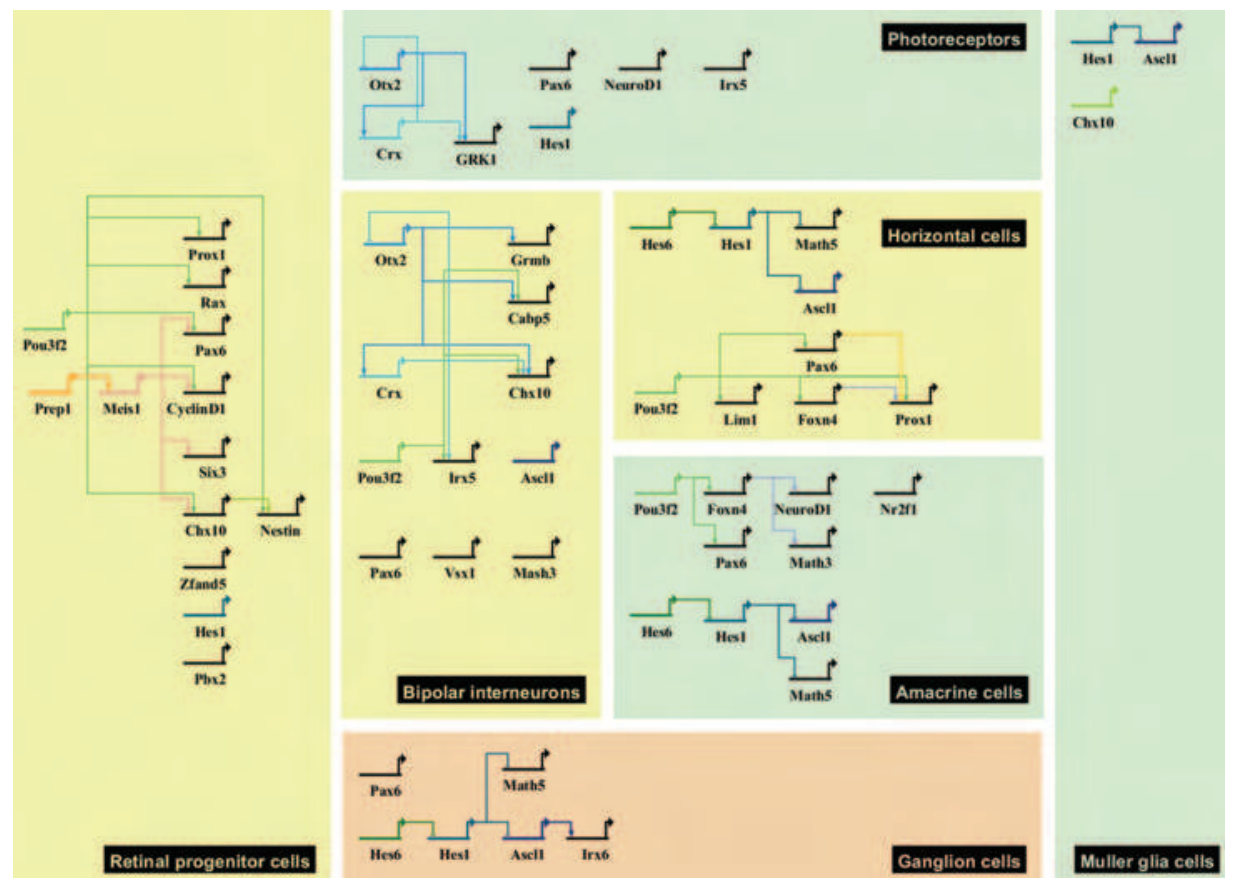

Fig. 3. Examples of transcriptional regulatory networks of embryonic retinal development. Genes and factors are connected with arrows or bars to indicate the promoting and suppressing relationship, respectively. 


\begin{tabular}{|c|l|}
\hline Factor name & Reference cited \\
\hline Cabp5 & (Kim et al., 2008a) \\
\hline Chx10 & (Hatakeyama et al., 2001) \\
\hline CyclinD1 & (Bessa et al., 2008; Heine et al., 2008) \\
\hline Foxn4 & (Shengguo Li, 2004) \\
\hline Grk1 & (Young and Young, 2007) \\
\hline Grmb & (Kim et al., 2008a) \\
\hline Hes6 & (Bae et al., 2000) \\
\hline Mash3 & (Hatakeyama et al., 2001; Satow et al., 2001) \\
\hline Math5 & (Lee et al., 2005) \\
\hline Nestin & (Rowan and Cepko, 2005) \\
\hline NeuroD1 & (Conte et al., 2010) \\
\hline Nr2f1 & (Inoue et al., 2010; Satoh et al., 2009) \\
\hline Otx2 & (Kim et al., 2008a; Young and Young, 2007) \\
\hline Pax6 & (Ferretti et al., 2006; Lee et al., 2005; Oliver et al., 1995) \\
\hline Prep1 & (Deflorian et al., 2004; Ferretti et al., 2006) \\
\hline Rax & (Heine et al., 2008; Martinez-de Luna et al., 2010) \\
\hline Six3 & (Oliver et al., 1995) \\
\hline Six6 & (Conte et al., 2010) \\
\hline
\end{tabular}

Table 5. A list of protein factors that interact with the 6 key trans-acting factors in a network model

In summary, the computational method we developed in this study can be described as following. First, experimentally verified enhancer elements can be selected from enhancer databases, e.g., the Vista Enhancer Browser, based on tissue/cell-specific expression patterns derived from the enhancer element and its flanking gene (Fig. 4A-B). These tissuespecific enhancer elements can be located in the non-coding regions in inter- or intragenetic sequences. Then, the trans-acting factor binding sites (TFBS) of all tissue-specific enhancer elements can be predicted using TFBS search tools such as TESS and MatInspector. Common binding sites shared by all tissue-specific enhancer elements or subsets of elements are later determined as shown in (Fig. 4C). Those common factors can be further analyzed according to their expression pattern. Only the ones with spatio-temporal expression patterns can be selected as key factors for constructing a tissue-specific transcriptional regulatory network. In addition, factors that interact with these key factors can also be found from the literature. Finally, these enhancers, genes, factors and interactions can be pieced together to build the network (Fig. 4D). 

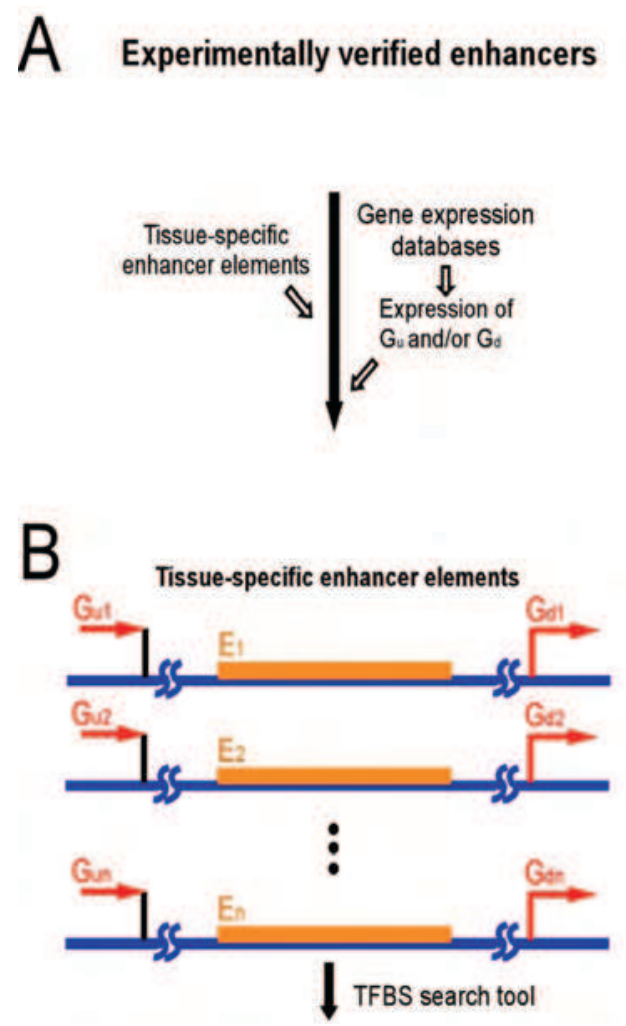

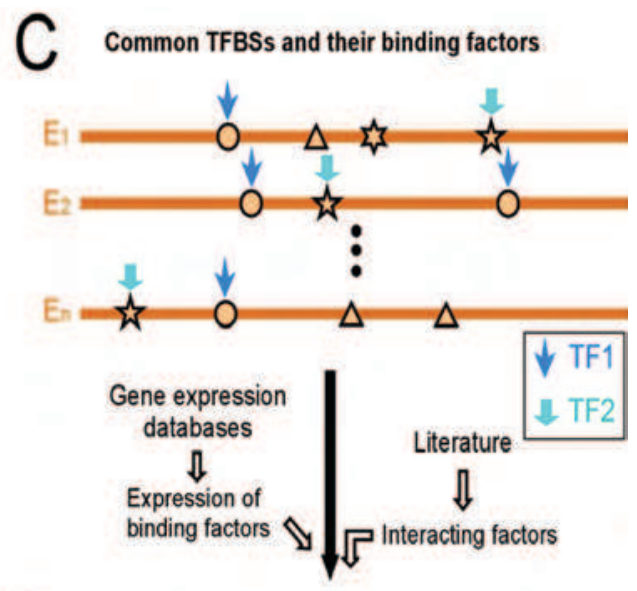

Transcriptional regulatory networks

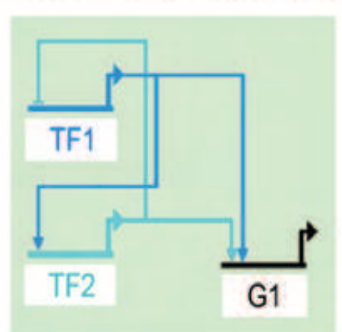

Fig. 4. Computational analysis of TFBSs and transcriptional regulatory networks for tissue/cell-specific gene expression. A. Selection of experimentally verified enhancer elements from enhancer databases. B. Depiction of enhancer elements and their flanking 
genes. Orange boxes represent tissue-specific enhancer elements. Red bars represent transcript start sites of downstream flanking genes. Black bars represent the end of the last exon of upstream flanking genes. Enhancer elements in the intronic region of a gene were not illustrated. C. Comparison of the trans-acting factor binding sites (TFBSs). Two examples of common TFBS-TF pairs are illustrated by pairs of circle/azure arrows and pentagon/cyan arrows. Other polygons on the enhancer elements (orange bars) represent binding sites that are not common to all members. D. A simple example of a tissue-specific transcriptional regulatory network generated with two key factors (TF1 and TF2) and their interacting genes $(\mathrm{G})$. The thick horizontal lines on top of factor and gene names (TF1, TF2 and G1) represent the cis-regulatory region of the corresponding genes. Arrows and bars terminating on this line illustrate the input from other factors, promoters or repressors, respectively. The arrow derived from the thick line represents the regulatory outputs. Abbreviation: E, enhancer element; G, gene; Gd, downstream gene; Gu, upstream gene; TF, trans-acting (e.g., transcription) factor; TFBS, transcription factor binding site.

\section{Conclusion}

In this study we have explored a new way of using existing TFBS-finding methods to predict trans-acting factors and networks that regulate tissue-specific gene expression (Fig. 4). As a proof-of-principle study, using this method, we have identified experimentally verified transcription factors (Pou3f2, Crx, Meis1, and Hes1) and their transcriptional regulatory networks that are known to be important for mouse embryonic retinal development. This not only provides a general idea about the development of the RPCs and retinal cell differentiation, but also validates the effectiveness of our newly developed method. Furthermore, we predicted that two other factors (Pbx2 and Tcf3, expressed in retina) may have a novel functional role in embryonic retinal development, which generates new hypotheses for future experimentation, i.e., to test the involvement of the two factors, Pbx2 and Tcf3, in the development of RPCs. This method is based on the assumption that non-coding DNA sequences contain signals regulating tissue-specific gene expression. The feasibility of this method relies on the existing data of experimentally verified tissue-specific enhancers (Visel et al., 2007) and available information of tissue-specific gene expression (Finger et al., 2011; Richardson et al., 2010). The identification of retina-specific trans-acting factors and networks indicates that our method is useful for the analysis of TFBSs and transcriptional regulatory networks. Since our method utilizes the existing/known information about tissue-specific enhancer elements and gene expression, we will not be able to identify novel factors that are involved in the transcriptional regulatory networks. In order to reconstruct a more sophisticated network in future studies, we will need to include all of the retina-specific enhancer elements. Finally, this method can be applied to the analysis of TFBSs and transcriptional regulatory networks in other tissue types.

\section{Acknowledgement}

This work is supported in part by grants (EY018738 and EY019094) from the National Institute of Health, the New Jersey Commission on Spinal Cord Research (10A-003-SCR1 and 08-3074-SCR-E-0), and Busch Biomedical Research Awards (6-49121). The authors thank the Cai lab members for helpful discussions and for proof-reading the manuscript. 


\section{References}

Bae, S., Bessho, Y., Hojo, M., and Kageyama, R. (2000). The bHLH gene Hes6, an inhibitor of Hes1, promotes neuronal differentiation. Development 127, 2933-2943.

Bailey, T.L., and Elkan, C. (1994). Fitting a mixture model by expectation maximization to discover motifs in biopolymers. Proc Int Conf Intell Syst Mol Biol 2, 28-36.

Bessa, J., Tavares, M.J., Santos, J., Kikuta, H., Laplante, M., Becker, T.S., Gómez-Skarmeta, J.L., and Casares, F. (2008). meis1 regulates cyclin D1 and c-myc expression, and controls the proliferation of the multipotent cells in the early developing zebrafish eye. Development 135, 799-803.

Cartharius, K., Frech, K., Grote, K., Klocke, B., Haltmeier, M., Klingenhoff, A., Frisch, M., Bayerlein, M., and Werner, T. (2005). MatInspector and beyond: promoter analysis based on transcription factor binding sites. Bioinformatics 21, 2933-2942.

Catena, R., Tiveron, C., Ronchi, A., Porta, S., Ferri, A., Tatangelo, L., Cavallaro, M., Favaro, R., Ottolenghi, S., Reinbold, R., et al. (2004). Conserved POU binding DNA sites in the Sox2 upstream enhancer regulate gene expression in embryonic and neural stem cells. J Biol Chem 279, 41846-41857.

Chang, C., Jacobs, Y., Nakamura, T., Jenkins, N., Copeland, N., and Cleary, M. (1997). Meis proteins are major in vivo DNA binding partners for wild-type but not chimeric Pbx proteins. Mol Cell Biol 17, 5679-5687.

Cheng, C.W., Chow, R.L., Lebel, M., Sakuma, R., Cheung, H.O.-L., Thanabalasingham, V., Zhang, X., Bruneau, B.G., Birch, D.G., Hui, C.-c., et al. (2005). The Iroquois homeobox gene, Irx5, is required for retinal cone bipolar cell development. Developmental Biology 287, 48-60.

Cohen, D.R., Cheng, C.W., Cheng, S.H., and Hui, C.-c. (2000). Expression of two novel mouse Iroquois homeobox genes during neurogenesis. Mechanisms of Development 91, 317-321.

Conte, I., Marco-Ferreres, R., Beccari, L., Cisneros, E., Ruiz, J.M., Tabanera, N., and Bovolenta, P. (2010). Proper differentiation of photoreceptors and amacrine cells depends on a regulatory loop between NeuroD and Six6. Development 137, 2307 2317.

Corbo, J.C., Lawrence, K.A., Karlstetter, M., Myers, C.A., Abdelaziz, M., Dirkes, W., Weigelt, K., Seifert, M., Benes, V., Fritsche, L.G., et al. (2010). CRX ChIP-seq reveals the cisregulatory architecture of mouse photoreceptors. Genome Res 20, 1512-1525.

de Diego Otero, Y., Bakker, C., Raghoe, P., Severijnen, L.A., Hoogeveen, A., Oostra, B., and Willemsen, R. (2000). Immunocytochemical characterization of FMRP, FXR1P and FXR2P during embryonic development in the mouse. Gene Function \& Disease 1, 2837.

Deflorian, G., Tiso, N., Ferretti, E., Meyer, D., Blasi, F., Bortolussi, M., and Argenton, F. (2004). Prep1.1 has essential genetic functions in hindbrain development and cranial neural crest cell differentiation. Development 131, 613-627.

Diez-Roux, G., Banfi, S., Sultan, M., Geffers, L., Anand, S., Rozado, D., Magen, A., Canidio, E., Pagani, M., Peluso, I., et al. (2011). A high-resolution anatomical atlas of the transcriptome in the mouse embryo. PLoS biology 9, e1000582. 
Ferretti, E., Villaescusa, J.C., Di Rosa, P., Fernandez-Diaz, L.C., Longobardi, E., Mazzieri, R., Miccio, A., Micali, N., Selleri, L., Ferrari, G., et al. (2006). Hypomorphic Mutation of the TALE Gene Prep1 (pKnox1) Causes a Major Reduction of Pbx and Meis Proteins and a Pleiotropic Embryonic Phenotype. Mol Cell Biol 26, 56505662 .

Finger, J.H., Smith, C.M., Hayamizu, T.F., McCright, I.J., Eppig, J.T., Kadin, J.A., Richardson, J.E., and Ringwald, M. (2011). The mouse Gene Expression Database (GXD): 2011 update. Nucleic Acids Research 39, D835-D841.

Frazer, K.A., Pachter, L., Poliakov, A., Rubin, E.M., and Dubchak, I. (2004). VISTA: computational tools for comparative genomics. Nucleic Acids Research 32, W273W279.

French, C.R., Erickson, T., Callander, D., Berry, K.M., Koss, R., Hagey, D.W., Stout, J., Wuennenberg-Stapleton, K., Ngai, J., Moens, C.B., et al. (2007). Pbx homeodomain proteins pattern both the zebrafish retina and tectum. BMC Dev Biol 7, 85.

Gray, P.A., Fu, H., Luo, P., Zhao, Q., Yu, J., Ferrari, A., Tenzen, T., Yuk, D.I., Tsung, E.F., Cai, Z., et al. (2004). Mouse brain organization revealed through direct genome-scale TF expression analysis. Science 306, 2255-2257.

Hatakeyama, J., Tomita, K., Inoue, T., and Kageyama, R. (2001). Roles of homeobox and bHLH genes in specification of a retinal cell type. Development 128, 1313-1322.

Heine, P., Dohle, E., Bumsted-O'Brien, K., Engelkamp, D., and Schulte, D. (2008). Evidence for an evolutionary conserved role of homothorax/Meis1/2 during vertebrate retina development. Development 135, 805-811.

Hsiau, T.H., Diaconu, C., Myers, C.A., Lee, J., Cepko, C.L., and Corbo, J.C. (2007). The cisregulatory logic of the mammalian photoreceptor transcriptional network. PLoS One 2, e643.

Hu, J., Wan, J., Hackler, L., Jr., Zack, D.J., and Qian, J. (2010). Computational analysis of tissue-specific gene networks: application to murine retinal functional studies. Bioinformatics 26, 2289-2297.

Inoue, M., Iida, A., Satoh, S., Kodama, T., and Watanabe, S. (2010). COUP-TFI and -TFII nuclear receptors are expressed in amacrine cells and play roles in regulating the differentiation of retinal progenitor cells. Experimental Eye Research 90, 4956.

Kent, W.J., Sugnet, C.W., Furey, T.S., Roskin, K.M., Pringle, T.H., Zahler, A.M., and Haussler, D. (2002). The human genome browser at UCSC. Genome Res 12, 9961006.

Kerschensteiner, D., Liu, H., Cheng, C.W., Demas, J., Cheng, S.H., Hui, C.-c., Chow, R.L., and Wong, R.O.L. (2008). Genetic Control of Circuit Function: Vsx1 and Irx5 Transcription Factors Regulate Contrast Adaptation in the Mouse Retina. J Neurosci 28, 2342-2352.

Kim, D.S., Matsuda, T., and Cepko, C.L. (2008a). A Core Paired-Type and POU Homeodomain-Containing Transcription Factor Program Drives Retinal Bipolar Cell Gene Expression. J Neurosci 28, 7748-7764. 
Kim, D.S., Matsuda, T., and Cepko, C.L. (2008b). A core paired-type and POU homeodomain-containing transcription factor program drives retinal bipolar cell gene expression. J Neurosci 28, 7748-7764.

Knuppel, R., Dietze, P., Lehnberg, W., Frech, K., and Wingender, E. (1994). TRANSFAC retrieval program: a network model database of eukaryotic transcription regulating sequences and proteins. Journal of computational biology : a journal of computational molecular cell biology 1, 191-198.

Kumar, J.P. (2009). The molecular circuitry governing retinal determination. Biochim Biophys Acta 1789, 306-314.

Le, T.T., Wroblewski, E., Patel, S., Riesenberg, A.N., and Brown, N.L. (2006). Math5 is required for both early retinal neuron differentiation and cell cycle progression. Developmental Biology 295, 764-778.

Lee, H.Y., Wroblewski, E., Philips, G.T., Stair, C.N., Conley, K., Reedy, M., Mastick, G.S., and Brown, N.L. (2005). Multiple requirements for Hes1 during early eye formation. Developmental Biology 284, 464-478.

Leo M. Chalupa, R.W.W., ed. (2008). Eye, Retina, and Visual System of the Mouse (The MIT Press).

Longabaugh, W.J.R., Davidson, E.H., and Bolouri, H. (2009). Visualization, documentation, analysis, and communication of large-scale gene regulatory networks. Biochimica et Biophysica Acta (BBA) - Gene Regulatory Mechanisms 1789, 363-374.

Martinez-de Luna, R.I., Moose, H.E., Kelly, L.E., Nekkalapudi, S., and El-Hodiri, H.M. (2010). Regulation of retinal homeobox gene transcription by cooperative activity among cis-elements. Gene 467, 13-24.

McEvilly, R.J., de Diaz, M.O., Schonemann, M.D., Hooshmand, F., and Rosenfeld, M.G. (2002). Transcriptional regulation of cortical neuron migration by POU domain factors. Science 295, 1528-1532.

Mummenhoff, J., Houweling, A.C., Peters, T., Christoffels, V.M., and Rüther, U. (2001). Expression of Irx6 during mouse morphogenesis. Mechanisms of Development 103, 193-195.

Oliver, G., Mailhos, A., Wehr, R., Copeland, N.G., Jenkins, N.A., and Gruss, P. (1995). Six3, a murine homologue of the sine oculis gene, demarcates the most anterior border of the developing neural plate and is expressed during eye development. Development 121, 4045-4055.

Peng, G.-H., Ahmad, O., Ahmad, F., Liu, J., and Chen, S. (2005). The photoreceptorspecific nuclear receptor Nr2e3 interacts with $\mathrm{Crx}$ and exerts opposing effects on the transcription of rod versus cone genes. Human Molecular Genetics 14, 747764.

Portales-Casamar, E., Thongjuea, S., Kwon, A.T., Arenillas, D., Zhao, X., Valen, E., Yusuf, D., Lenhard, B., Wasserman, W.W., and Sandelin, A. (2010). JASPAR 2010: the greatly expanded open-access database of transcription factor binding profiles. Nucleic Acids Research 38, D105-110.

Richardson, L., Venkataraman, S., Stevenson, P., Yang, Y., Burton, N., Rao, J., Fisher, M., Baldock, R.A., Davidson, D.R., and Christiansen, J.H. (2010). EMAGE mouse 
embryo spatial gene expression database: 2010 update. Nucleic Acids Research 38, D703-D709.

Rowan, S., and Cepko, C.L. (2005). A POU factor binding site upstream of the Chx10 homeobox gene is required for Chx10 expression in subsets of retinal progenitor cells and bipolar cells. Developmental Biology 281, 240-255.

Sandelin, A., Alkema, W., Engstrom, P., Wasserman, W.W., and Lenhard, B. (2004). JASPAR: an open-access database for eukaryotic transcription factor binding profiles. Nucleic Acids Research 32, D91-94.

Satoh, S., Tang, K., Iida, A., Inoue, M., Kodama, T., Tsai, S.Y., Tsai, M.-J., Furuta, Y., and Watanabe, S. (2009). The Spatial Patterning of Mouse Cone Opsin Expression Is Regulated by Bone Morphogenetic Protein Signaling through Downstream Effector COUP-TF Nuclear Receptors. J Neurosci 29, 12401-12411.

Satow, T., Bae, S.-K., Inoue, T., Inoue, C., Miyoshi, G., Tomita, K., Bessho, Y., Hashimoto, N., and Kageyama, R. (2001). The Basic Helix-Loop-Helix Gene hesr2 Promotes Gliogenesis in Mouse Retina. J Neurosci 21, 1265-1273.

Schug, J. (2002). Using TESS to Predict Transcription Factor Binding Sites in DNA Sequence (John Wiley \& Sons, Inc.).

Shengguo Li, Z.M., Xuejie Yang, (2004). Foxn4 Controls the Genesis of Amacrine and Horizontal Cells by Retinal Progenitors. Neuron 43, 795-807.

Sicinski, P., Donaher, J.L., Parker, S.B., Li, T., Fazeli, A., Gardner, H., Haslam, S.Z., Bronson, R.T., Elledge, S.J., and Weinberg, R.A. (1995). Cyclin D1 provides a link between development and oncogenesis in the retina and breast. Cell 82, 621630.

Sugitani, Y., Nakai, S., Minowa, O., Nishi, M., Jishage, K., Kawano, H., Mori, K., Ogawa, M., and Noda, T. (2002). Brn-1 and Brn-2 share crucial roles in the production and positioning of mouse neocortical neurons. Genes Dev 16, 1760-1765.

Swaroop, A., Kim, D., and Forrest, D. (2010). Transcriptional regulation of photoreceptor development and homeostasis in the mammalian retina. Nat Rev Neurosci 11, 563576.

Tang, K., Xie, X., Park, J.I., Jamrich, M., Tsai, S., and Tsai, M.J. (2010). COUP-TFs regulate eye development by controlling factors essential for optic vesicle morphogenesis. Development $137,725-734$.

Valouev, A., Johnson, D.S., Sundquist, A., Medina, C., Anton, E., Batzoglou, S., Myers, R.M., and Sidow, A. (2008). Genome-wide analysis of transcription factor binding sites based on ChIP-Seq data. Nat Meth 5, 829-834.

Visel, A., Blow, M.J., Li, Z., Zhang, T., Akiyama, J.A., Holt, A., Plajzer-Frick, I., Shoukry, M., Wright, C., Chen, F., et al. (2009). ChIP-seq accurately predicts tissue-specific activity of enhancers. Nature $457,854-858$.

Visel, A., Minovitsky, S., Dubchak, I., and Pennacchio, L.A. (2007). VISTA Enhancer Browser - a database of tissue-specific human enhancers. Nucleic Acids Research 35, D88-D92.

Wall, D.S., Mears, A.J., McNeill, B., Mazerolle, C., Thurig, S., Wang, Y., Kageyama, R., and Wallace, V.A. (2009). Progenitor cell proliferation in the retina is dependent on Notch-independent Sonic hedgehog/Hes1 activity. J Cell Biol 184, 101-112. 
Young, J.E., Kasperek, E.M., Vogt, T.M., Lis, A., and Khani, S.C. (2007). Conserved interactions of a compact highly active enhancer/promoter upstream of the rhodopsin kinase (GRK1) gene. Genomics 90, 236-248. 


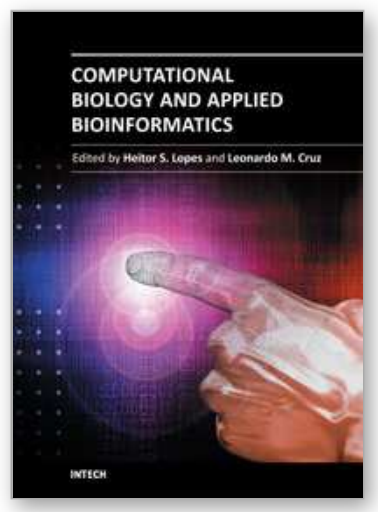

\section{Computational Biology and Applied Bioinformatics}

Edited by Prof. Heitor Lopes

ISBN 978-953-307-629-4

Hard cover, 442 pages

Publisher InTech

Published online 02, September, 2011

Published in print edition September, 2011

Nowadays it is difficult to imagine an area of knowledge that can continue developing without the use of computers and informatics. It is not different with biology, that has seen an unpredictable growth in recent decades, with the rise of a new discipline, bioinformatics, bringing together molecular biology, biotechnology and information technology. More recently, the development of high throughput techniques, such as microarray, mass spectrometry and DNA sequencing, has increased the need of computational support to collect, store, retrieve, analyze, and correlate huge data sets of complex information. On the other hand, the growth of the computational power for processing and storage has also increased the necessity for deeper knowledge in the field. The development of bioinformatics has allowed now the emergence of systems biology, the study of the interactions between the components of a biological system, and how these interactions give rise to the function and behavior of a living being. This book presents some theoretical issues, reviews, and a variety of bioinformatics applications. For better understanding, the chapters were grouped in two parts. In Part I, the chapters are more oriented towards literature review and theoretical issues. Part II consists of application-oriented chapters that report case studies in which a specific biological problem is treated with bioinformatics tools.

\section{How to reference}

In order to correctly reference this scholarly work, feel free to copy and paste the following:

Ying Li, Haiyan Huang and Li Cai (2011). Prediction of Transcriptional Regulatory Networks for Retinal Development, Computational Biology and Applied Bioinformatics, Prof. Heitor Lopes (Ed.), ISBN: 978-953-307629-4, InTech, Available from: http://www.intechopen.com/books/computational-biology-and-appliedbioinformatics/prediction-of-transcriptional-regulatory-networks-for-retinal-development

\section{INTECH}

open science | open minds

\author{
InTech Europe \\ University Campus STeP Ri \\ Slavka Krautzeka 83/A \\ 51000 Rijeka, Croatia \\ Phone: +385 (51) 770447 \\ Fax: +385 (51) 686166 \\ www.intechopen.com
}

\author{
InTech China \\ Unit 405, Office Block, Hotel Equatorial Shanghai \\ No.65, Yan An Road (West), Shanghai, 200040, China \\ 中国上海市延安西路65号上海国际贵都大饭店办公楼 405 单元 \\ Phone: +86-21-62489820 \\ Fax: +86-21-62489821
}


(C) 2011 The Author(s). Licensee IntechOpen. This chapter is distributed under the terms of the Creative Commons Attribution-NonCommercialShareAlike-3.0 License, which permits use, distribution and reproduction for non-commercial purposes, provided the original is properly cited and derivative works building on this content are distributed under the same license. 